\title{
APLIKASI E-COMMERCE: STUDI KASUS PADA PT EIGL
}

\author{
Rudy; Nicholas H.; Fransisca; Theodore Silvie T. \\ Information Systems Department, School of Information Systems, Binus University \\ Jl. K.H. Syahdan No. 9, Palmerah, Jakarta Barat 11480 \\ rudy@binus.edu
}

\begin{abstract}
The cosmetics trend is apparently in line with the fashion trend which is likely to change from time to time. Competition in the cosmetics industry today, coupled with the increasing number of imported cosmetic products on the market require cosmetic companies to continue innovating and taking advantage of opportunities as possible. A very rapid development of Internet opens opportunities for cosmetic companies, especially PT EIGL, to be able to offer products to Internet users. The purpose of this study is to build a prototype e-commerce application, preceded by identifying the odds and the readiness of companies in conducting e-commerce. The methodology used is the analysis of the company's readiness using the preparation analysis of a market opportunity and design application using object-oriented approach. The research results in an e-commerce application that consists of the front-end and content management system. From this study it can be concluded that PT EIGL retains the opportunity to run e-commerce. To facilitate the company in managing ecommerce website a content management system is created in an easy way to operate.
\end{abstract}

Keywords: cosmetic products, e-commerce application, object-oriented approach, content management system

\begin{abstract}
ABSTRAK
Tren kosmetik saat ini sejalan dengan tren fashion yang selalu berubah dari waktu ke waktu. Ketatnya persaingan industri kosmetik saat ini serta ditambah dengan semakin banyaknya produk kosmetik impor dipasaran menuntut produsen kosmetik agar terus dapat berinovasi dan memanfaatkan peluang semaksimal mungkin. Perkembangan internet yang sangat cepat membuka peluang bagi perusahaan khususnya PT EIGL untuk dapat menawarkan produk yang ditawarkan kepada para pemakai internet. Tujuan penelitian ini adalah membangun aplikasi prototipe e-commerce yang didahului dengan mengetahui peluang dan kesiapan perusahaan dalam melakukan e-commerce. Metodologi yang digunakan yaitu analisis kesiapan perusahaan menggunakan analisis penyusunan peluang pasar dan perancangan aplikasi dengan pendekatan berorientasi objek. Hasil yang didapat adalah aplikasi e-commerce yang terdiri dari bagian front-end dan sistem manajemen konten. Dari penelitian ini dapat disimpulkan bahwa PT EIGL memiliki peluang untuk menjalankan ecommerce. Untuk mempermudah perusahaan dalam mengatur website e-commerce dibuatkan sistem manajemen konten yang mudah dioperasikan.
\end{abstract}

Kata kunci: produk kosmetik, aplikasi e-commerce, pendekatan berorientasi objek, sistem manajemen konten 


\section{PENDAHULUAN}

Tren kosmetik saat ini sejalan dengan tren fashion yang selalu berubah dari waktu ke waktu sesuai dengan perkembangan zaman. Untuk memenuhi tuntutan masyarakat, tidak heran apabila berbagai industri kosmetik berlomba-lomba menciptakan berbagai macam produk kecantikan. Mulai dari bedak, pembersih muka, penghilang jerawat, pemutih wajah, dan berbagai macam kegunaan lainnya. Saat ini tidak hanya industri kosmetik dalam negeri saja yang terus bersaing untuk memperebutkan pasar bahkan produk kosmetik impor juga semakin meningkat di pasaran. Hal ini diperkuat dengan adanya pernyataan dari Ketua Perhimpunan Perusahaan dan Asosiasi Kosmetik Indonesia (PPAK1), Putri Kuswis, dalam artikel Harian Ekonomi Neraca, 24 Aug 2010 yang menyatakan, "Pada tahun 2009, nilai penjualan produk kosmetik mencapai Rp 10 triliun, sementara tahun ini angkanya diperkirakan tidak bergerak naik akibat serbuan produk kosmetik impor yang antara lain berasal dari China, Taiwan, Thailand dan Korea. Nilai penjualan kosmetik stagnan karena di lapangan produk jamu dan kosmetik impor makin deras masuk ke pasaran. Putri menjelaskan bahwa sebagian produk kosmetik yang beredar di pasaran merupakan produk ilegal, tidak memiliki izin edar dari Badan Pengawas Obat dan Makanan (BPOM) dan tidak mencantumkan label berbahasa Indonesia sesuai ketentuan. Menurut Putri, tren membanjirnya produk impor kosmetik dan jamu yang mudah masuk ke pasar dalam negeri terjadi semenjak adanya AC-FTA khususnya ketika produk jamu dan kosmetik sudah mengalami penghapusan tarif 0\%”. (Sumber: Bataviase.co.id).

Dari potongan berita di atas, dapat dilihat bagaimana ketatnya persaingan industri kosmetik saat ini apalagi dengan semakin banyaknya produk kosmetik impor dipasaran menyebabkan tingkat penjualan kosmetik lokal tidak mengalami pertumbuhan. Oleh sebab itu, untuk mencapai suatu keberhasilan industri kosmetik harus mulai melakukan inovasi dan kreasi di bidang produksi, pemasaran, distribusi, dan pelayanan kepada pelanggan. Salah satu media yang dapat digunakan saat ini adalah internet. Melalui internet pelanggan dapat melakukan transaksi pembelian produk kapanpun dan dimanapun. Peluang tersebut dapat dimanfaatkan oleh PT EIGL untuk membuat aplikasi $e$ commerce untuk melayani proses penjualan, pembayaran serta pengiriman produk.

Menurut Laudon and Laudon (2004, p24), e-commerce adalah proses penjualan pembelian barang dan jasa secara elektronik dengan transaksi bisnis terkomputerisasi menggunakan internet, jaringan dan teknologi digital lainnya. Menurut Rayport and Jaworski (2003, p.4), e-commerce adalah pertukaran antar bagian yang dihubungkan dengan teknologi (baik individual atau organisasi) juga diaktivitas dalam atau antar organisasi berbasis elektronik yang mendukung pertukaran seperti itu. Menurut O’Brien (2005, p.12), e-commerce adalah pembelian dan penjualan, pemasaran dan pelayanan produk, jasa, dan informasi atas berbagai jenis jaringan komputer.

Pengembangan website ini diharapkan dapat membantu PT EIGL dalam memasarkan produk dan mempermudah proses penjualan sehingga proses bisnisnya menjadi lebih efektif dan efisien.

\section{METODE}

Metodologi yang digunakan terdiri dari dua tahapan, yaitu metode kesiapan perusahaan dengan menggunakan analisis penyusunan peluang pasar. Menurut Rayport dan Jaworski (2003, p.73) analisis peluang pasar adalah sebuah alat yang penting untuk pengusaha dan juga manajer senior yang sedang berusaha memperluas peluang bisnis yang ada atau memulai bisnis baru. Tujuan dari analisis ini adalah untuk mengidentifikasi peluang yang berpotensi tinggi dan memulai bentuk ide tentang elemen yang penting dari bisnis. Untuk menganalisis peluang pasar yang ada di perlukan sebuah kerangka kerja yang berguna untuk mendukung investigasi awal dari pencetusan ide-ide, terdapat 
tujuh kerangka untuk menganalisis peluang pasar: (1) identifikasi kebutuhan pelanggan yang belum terpenuhi atau terlayani; (2) identifikasi spesifik pelanggan yang akan dituju perusahaan; (3) menilai keunggulan kompetisi; (4) menilai sumber daya perusahaan dalam memberikan layanan; (5) menilai kesiapan pasar terhadap teknologi; (6) menentukan peluang yang ada; (7) menilai daya tarik peluang.

Selanjutnya digunakan metode perancangan aplikasi e-commerce melalui Object-Oriented Analysis and Design (OOAD) 'pendekatan berorientasi objek; yang digambarkan dengan notasi UML. Object-Oriented Analysis and Design (OOAD) adalah metode untuk menganalisis dan merancang sistem dengan pendekatan berorientasi object (Mathiassen et al, 2000, p.15). Mathiassen et al (2000, p.14) menambahkan bahwa terdapat empat aktivitas utama dalam OOAD yaitu problem domain, application domain analysis, architectural design dan componen design.

\section{HASIL DAN PEMBAHASAN}

\section{Analisis Peluang Pasar}

Untuk mengetahui peluang yang dimiliki dan kesiapan dari perusahaan terlebih dahulu dilakukan analisis peluang pasar, yang terdiri dari beberapa tahapan berikut ini.

\section{Identifikasi Kebutuhan Pelanggan yang Belum Terpenuhi}

Pada tahap ini dapat diidentifikasikan bahwa pelanggalan perusahaan membeli produk untuk keperluan pribadi dan untuk diberikan kepada rekan/saudara sebagai hadiah. Berdasarkan hasil kuesioner yang dilakukan terhadap pelanggan, diketahui bahwa pada umumnya pelanggan mendapatkan informasi melalui brosur, website marketing, dan dari mulut ke mulut. Proses pembeliannya sendiri dilakukan oleh pelanggan dengan cara datang langsung ke outlet perusahaan. Pada outlet pelanggan dapat memilih kategori produk yang dibutuhkan seperti Cleansers, Moisturizer, Specialties, Eye Care, Sunblock, Essential Oils, Masque Therapy, Body Care dan Vitamin. Kondisi yang berjalan ini masih dirasa kurang oleh pelanggan dikarenakan ada beberapa kebutuhan yang belum dapat dipenuhi di antaranya: informasi produk yang lebih spesifik, pemesanan dapat dilakukan dengan memanfaatkan internet, mengetahui status pemesanan dan pembayaran bagi pelanggan di luar kota.

\section{Identifikasi Spesifik Pelanggan yang Akan Dituju Perusahaan}

Pada tahapan ini perusahaan melakukan indentifikasi terhadap para pelanggan yang akan menjadi target pagi perusahaan. Identifikasi menggunakan parameter perilaku, geografi, demografi dan keuntungan. Penggunaan parameter tersebut karena mayoritas pelanggan yang membeli produk pada umumnya melakukan pertimbangan terhadap merek produk sesuai dengan kebutuhan pelanggan. Selain itu, lokasi, tujuan dan gender pelanggan juga turut berpengaruh terhadap pembelian produk.

\section{Menilai Keunggulan Kompetisi}

Dibandingkan dengan para pesaing PT EIGL memiliki beberapa keunggulan dan kelemahan yang harus diperbaiki agar dapat menjadi pemimpin pasar untuk industri kosmetik. Dari sisi harga yang ditawarkan untuk produk PT EIGL tidak berbeda dengan harga pada kompetitor, keunggulan PT EIGL terletak pada keragaman produk yang ditawarkan, sedangkan untuk distribusi PT EIGL masih belum tersebar secara merata di kota-kota besar di Indonesia. 


\section{Menilai Sumber Daya Perusahaan dalam Memberikan Layanan}

PT EIGL memiliki beberapa sumber daya yang dimiliki untuk memberikan layanan kepada para pelanggannya. Sumber daya yang berhadapan langsung dengan pelanggan, di antaranya: (1) outlet PT EIGL menyediakan kosmetik dengan kualitas dan daya tarik yang tinggi sehingga dapat menarik pelanggan untuk masuk, melihat, bahkan memungkinkan pelanggan untuk langsung mencoba kosmetik yang tersedia; (2) Layanan Pelanggan yang bersahabat dan siap melayani pesanan dan keluhan dari pelanggan serta memastikan bahwa produk yang dipesan oleh pelanggan telah sampai pada tujuan dan dalam kondisi baik; (3) PT EIGL merupakan perusahaan kometik yang berdiri di Indonesia sejak tahun 2008; (4) Tenaga penjual yang terdapat pada PT EIGL diwajibkan untuk mengikuti pelatihan pengenalan produk secara khusus sehingga dapat menjelaskan kegunaan dan keunggulan masing-masing produk dengan mengenal spesifikasi produk tersebut; (5) PT EIGL menggunakan jasa pengiriman terpercaya yang telah bekerjasama sejak perusahaan berdiri di Indonesia.

\section{Menilai Kesiapan Pasar terhadap Teknologi}

Dalam memasarkan produknya, PT EIGL menyadari bahwa banyak pelanggan yang menginginkan kemudahan dalam berbelanja. Hal ini menyebabkan perlunya sebuah aplikasi $e$ commerce dengan layanan low-bandwith untuk mengakses sebuah website. Populasi pengguna fasilitas internet yang terus meningkat menggambarkan bahwa masa depan bisnis yang berbasis $e$ commerce akan sangat mendukung perkembangan suatu perusahaan.

\section{Menentukan Peluang yang Ada}

Pada tahap ini akan dispesifikasikan kesempatan yang ada saat ini jika perusahaan menggunakan teknologi internet. Kesempatan-kesempatan tersebut dirumuskan dalam sebuah opportunity story yang terdiri dari: (1) target segment pada PT EIGL meliputi pelanggan atau individu dengan gender wanita. Nilai proporsi yang dapat ditawarkan oleh PT EIGL apabila menggunakan teknologi internet adalah kelengkapan informasi mengenai produk yang ditawarkan serta informasi mengenai seluruh produk dan tentang perusahan sehingga pelanggan dapat mendapatkan informasi yang akurat; (2) kuntungan pelanggan yaitu dapat melakukan transaksi kapanpun dan di mana saja. Selain itu, pelanggan juga akan lebih leluasa dalam memilih produk yang mereka suka dan ingin dibeli dengan didukung oleh layanan dari layanan pelanggan secara online; (3) sumber daya utama yang dibutuhkan untuk memberikan keuntungan dan nilai lebih bagi pelanggan adalah ketersediaan produk yang berkualitas dengan harga yang terjangkau untuk kalangan menengah serta karyawan berpengalaman yang dapat menangani proses transaksi dan melayani pelanggan secara online.; (4) alasan yang membuat pelanggan selalu percaya untuk berbelanja di PT EIGL secara online adalah latar belakang dari perusahaan yang sudah berpengalaman selama 24 tahun dalam bidang perawatan kulit, perawatan rambut serta industri kesehatan dan kecantikan. Selain itu produk PT EIGL tidak mengandung bahan kimia berbahaya dan sudah terdaftar pada BPOM; (5) PT EIGL mendapatkan sumber daya produk berkualitas langsung dari pabrik di Malaysia dan PT EIGL juga memiliki sumber daya karyawan yang berpengalaman di bidang kecantikan; (6) memaksimalkan peluang PT EIGL menggunakan teknologi internet yang diharapkan dapat meningkatkan pelayanan kepada pelanggan atau meningkatkan kepuasan pelanggan sehingga dapat menambah jumlah pelanggan. Pertambahan jumlah pelanggan akan memperluas pangsa pasar PT EIGL sehingga akan meningkatkan keuntungan yang diperoleh; (7) besarnya peluang penerapan e-commerce pada PT. EIG Lexwel akan memudahkan pelanggan dalam berbelanja serta memberikan keleluasaan kepada pelanggan dalam memilih produk melalui media website yang disediakan.

Berdasarkan atas analisis di atas dapat dikatakan bahwa PT EIGL dapat memanfaatkan $e$ commerce untuk meningkat daya saing perusahaan. 


\section{Rancangan Aplikasi}

Pada proses perancangan ini, obyek yang dapat diidentifikasi; produk, kategori produk, merk produk, pemesanan, detail pemesanan, pelanggan, status pemesanan dan konfirmasi pembayaran. Gambar 1 menunjukkan hubungan antar class (class diagram) pada aplikasi e-commerce PT EIGL yang dirancang.

Gambar 2 adalah rancangan layar website e-commerce untuk pendaftaran. Pada layar ini calon anggota akan memberikan informasi data diri. Selain itu, pendaftar menentukan username dan password yang akan digunakan untuk masuk ke dalam halaman anggota (member area). Pada halaman anggota, para anggota dapat mengetahui status pesanan (order status) dan melakukan konfirmasi pembayaran. Pada Gambar 3 adalah rancangan layar tambah kategori. Rancangan layar ini merupakan salah satu layar pada sistem manajemen konten untuk website e-commerce PT EIGL. Pada rancangan layar tambah kategori, seorang administrator dapat menambahkan kategori produk disertai dengan deskripsi singkat dari kategori produk yang dimaksud serta gambar untuk kategori produk.

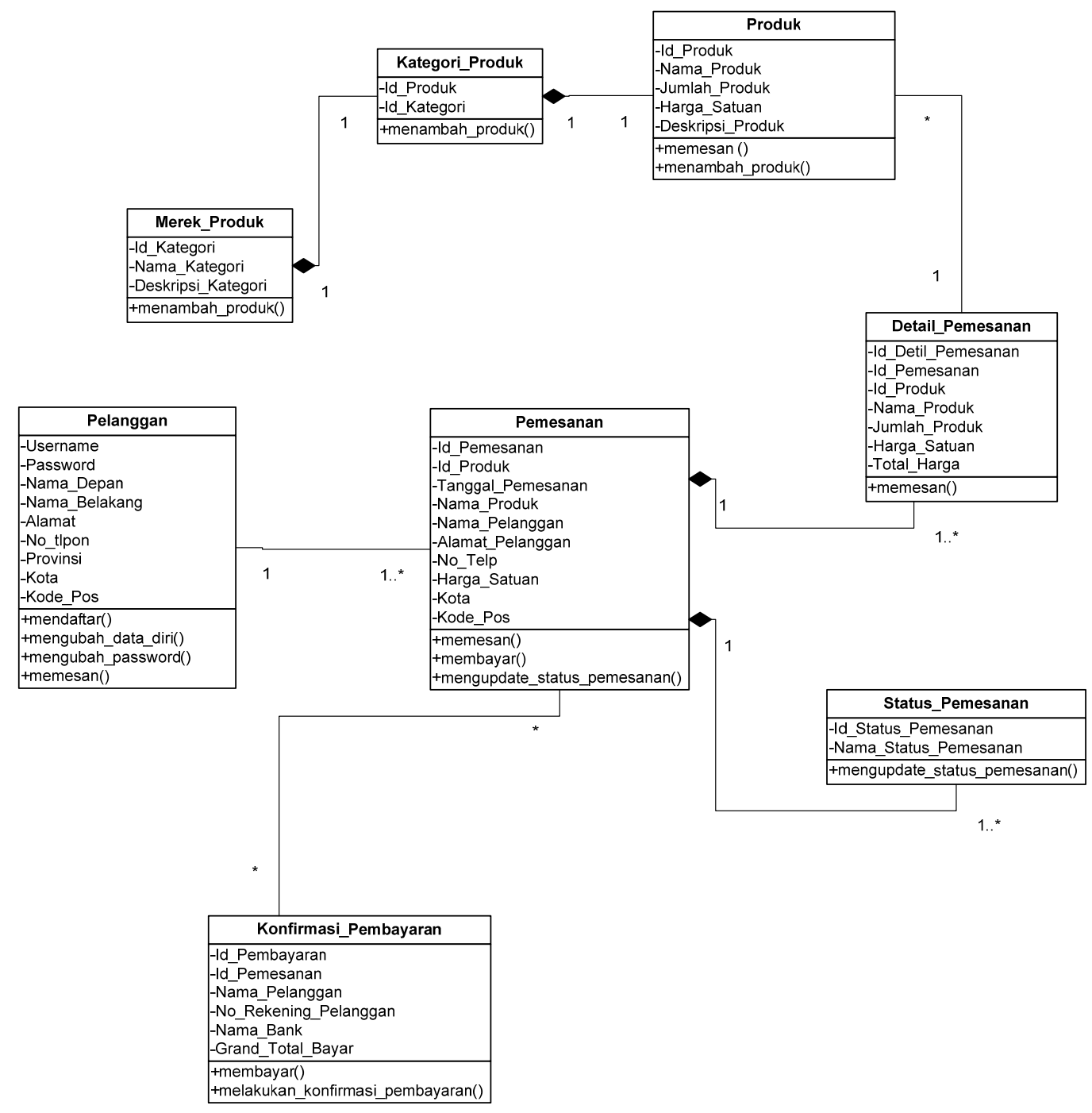

Gambar 1. Class Diagram. 


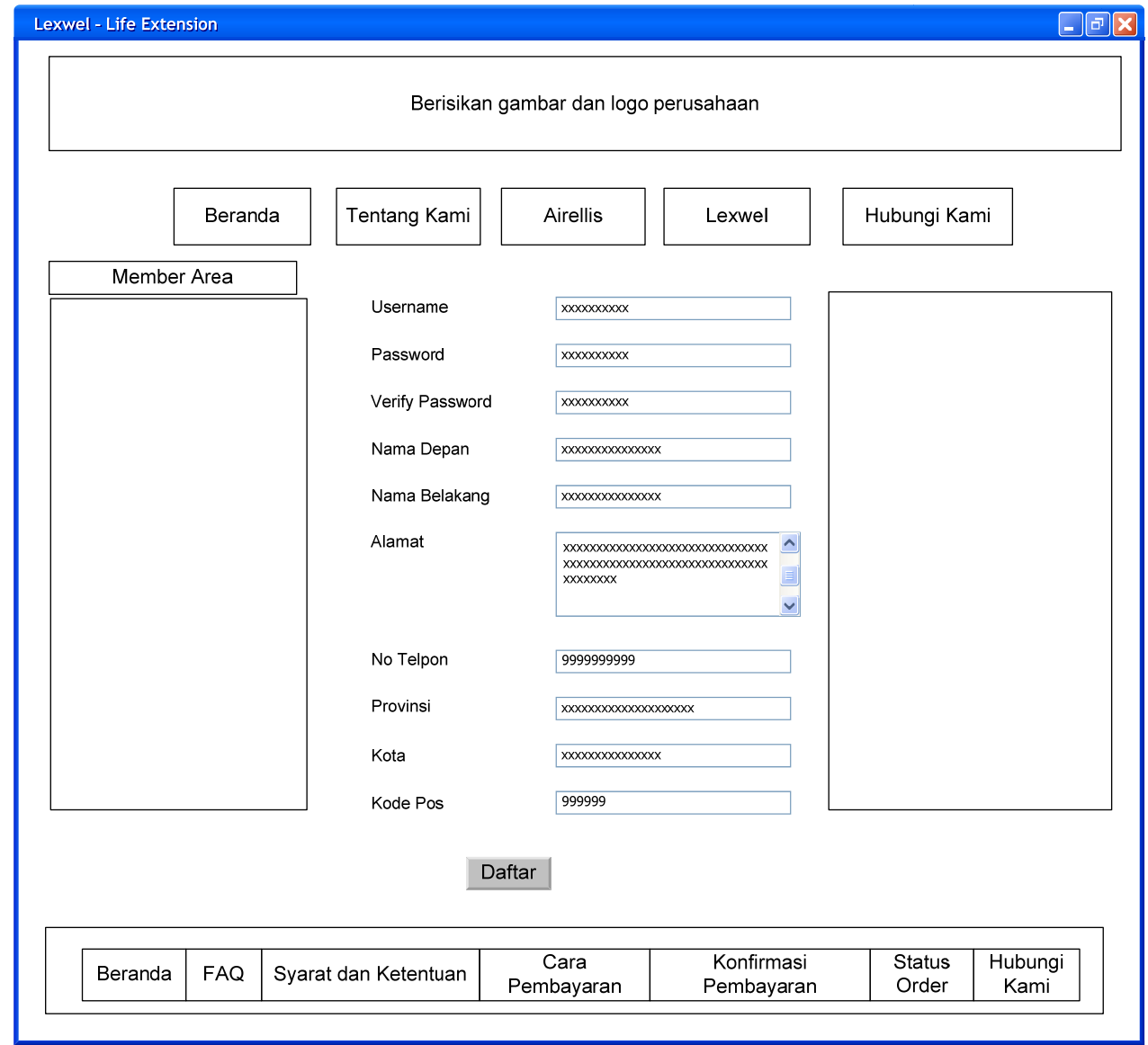

Gambar 2. Rancangan layar pendaftaran.

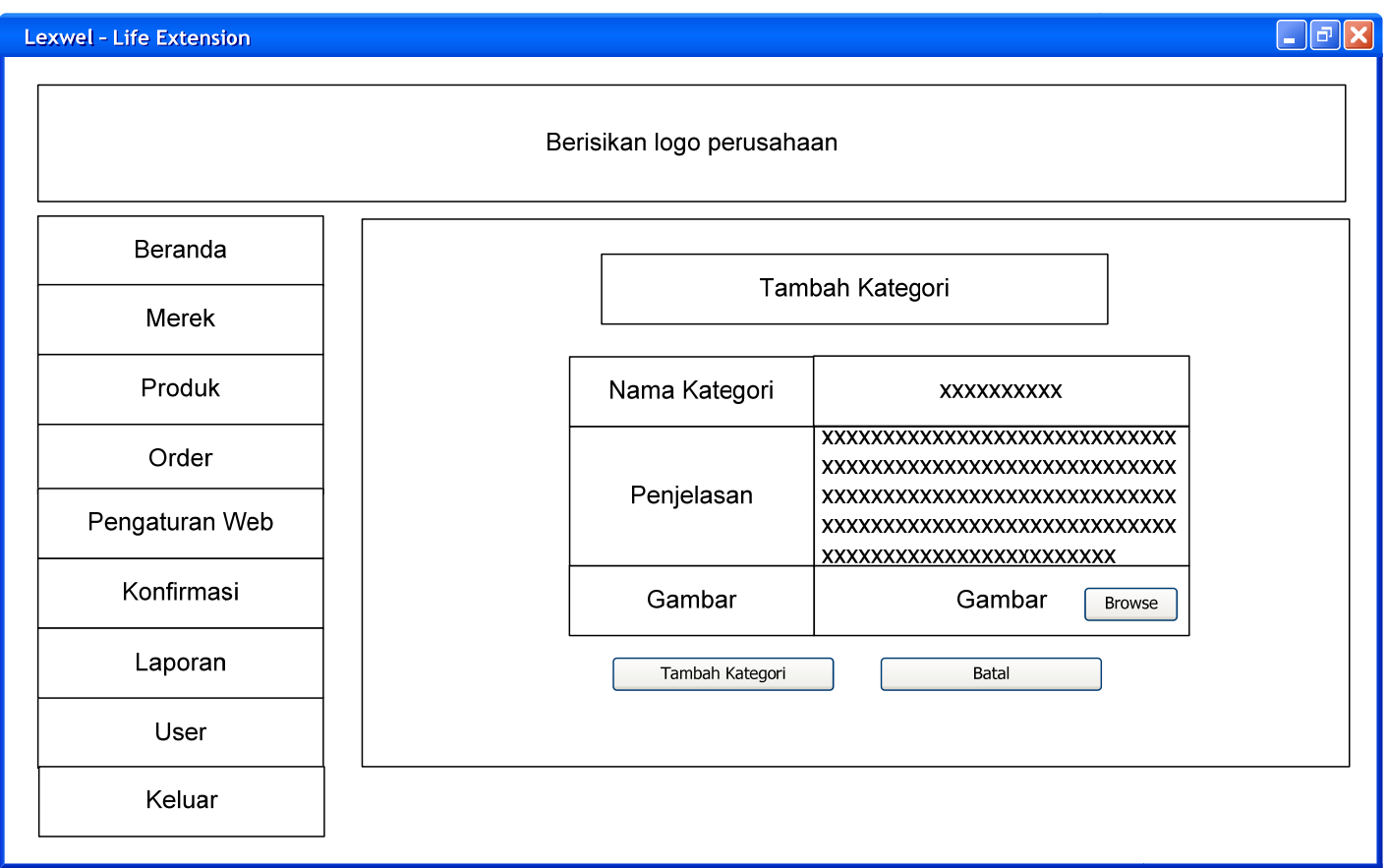

Gambar 3. Rancangan layar tambah kategori. 


\section{Protipe Aplikasi E-Commerce}

Prototipe aplikasi dibangun dengan menggunakan bahasa pemograman PHP dan dengan basisdata MySQL. Aplikasi dibangun terdiri dari bagian front end yang akan digunakan atau dipublikasikan kepada khalayak umum dan sistem manajemen konten (back end) yang akan digunakan oleh pihak perusahaan dalam hal ini administrator website.

Pertama kali mengakses website e-commerce PT EIGL, pengunjung akan masuk kedalam halaman "Beranda" - di sini pengunjung akan dapat memilihi tipe produk yang diinginkan. Halaman "Tentang Kami” berisikan informasi mengenai perusahaan. Untuk informasi produk pada website ecommerce ini mencantumkan menu "Airrellis" dan "Lexwel". Sedangkan menu "Hubungi Kami" berisikan informasi mengenai lokasi dan kontak dari PT EIGL yang dapat dihubungi.

Gambar 4 di bawah ini merupakan antarmuka halaman produk. Pada halaman ini pengunjung dapat melihat secara lengkap dari kategori produk sampai dengan detail produk setelah memilih "Airellis" ataupun "Lexwell”. Detil produk dapat dilihat dengan memilih/mengklik dari masingmasing produk, setelah masuk ke dalam "Halaman Produk Detail” (Gambar 5), pengunjung akan dapat melakukan transaksi pemesanan dengan memilih/mengklik tombol tambahkan ke keranjang. Proses pemesanan diakhiri dengan memasukan data diri berserta alamat lengkap dari pemesanan, sistem akan memberikan kode pemesanan kepada pemesan, sebagai acuan untuk melakukan pembayaran.

Gambar 6 dan 7 adalah halaman dari sistem manajemen konten, website e-commerce yang dibangun dilengkapi dengan sistem manajemen konten, di mana pihak perusahaan dapat mengelola website dengan baik, dapat dengan mudah menambahkan produk, melakukan konfirmasi pesanan, melakukan editing terhadap konten yang sudah ada sampai dengan membuat laporan.

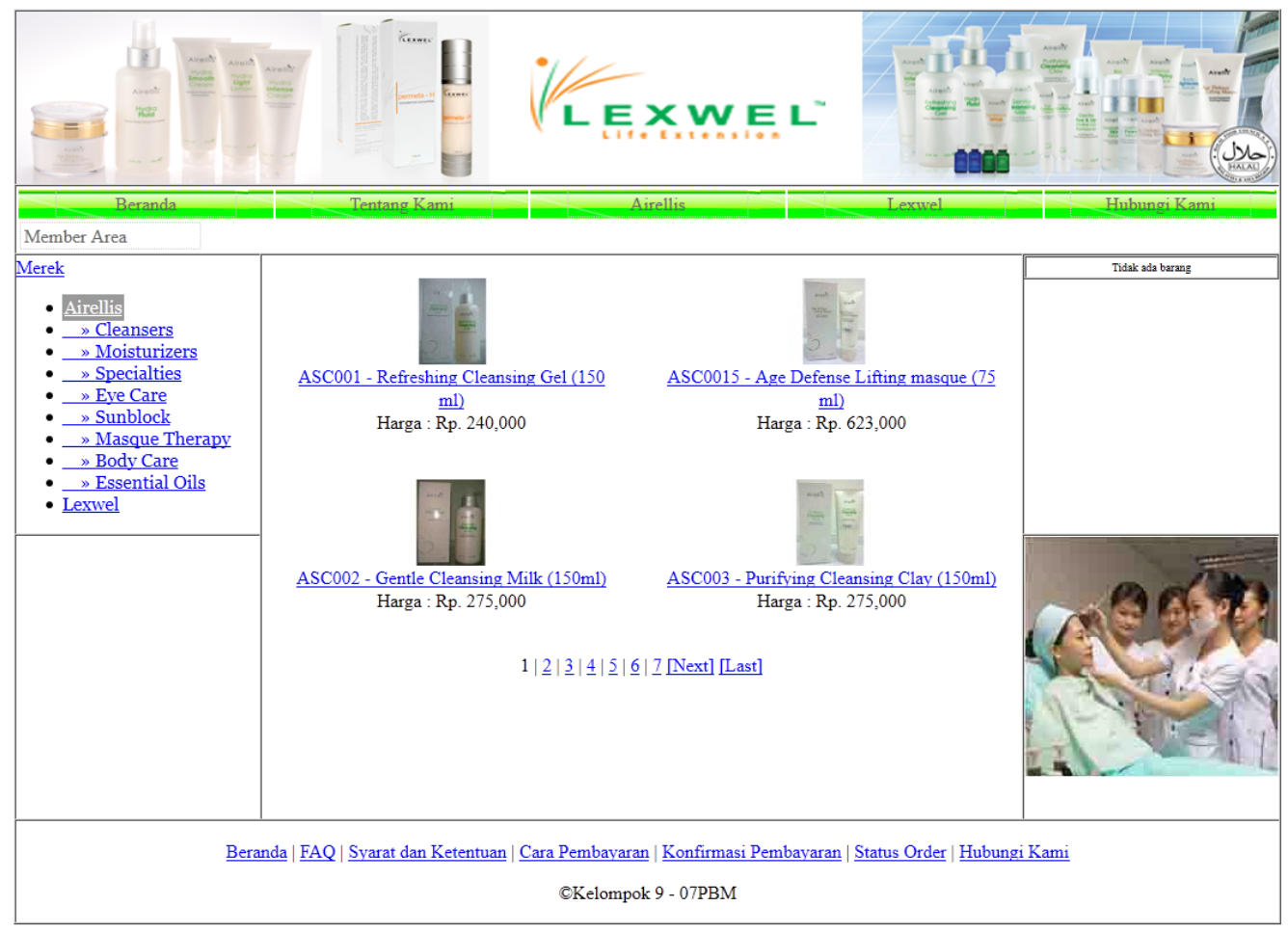

Gambar 4. Halaman produk. 


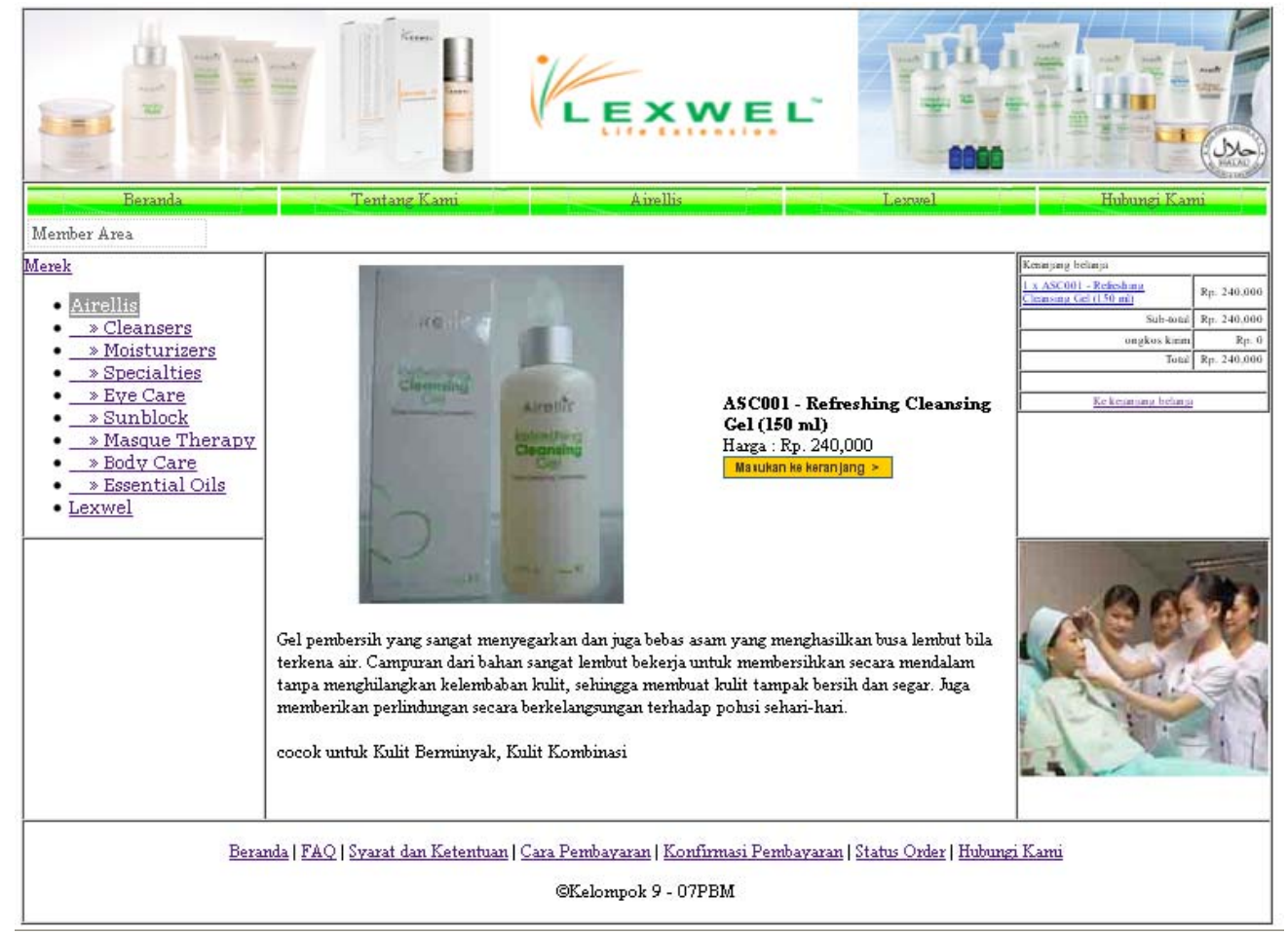

Gambar 5. Halaman produk detil.

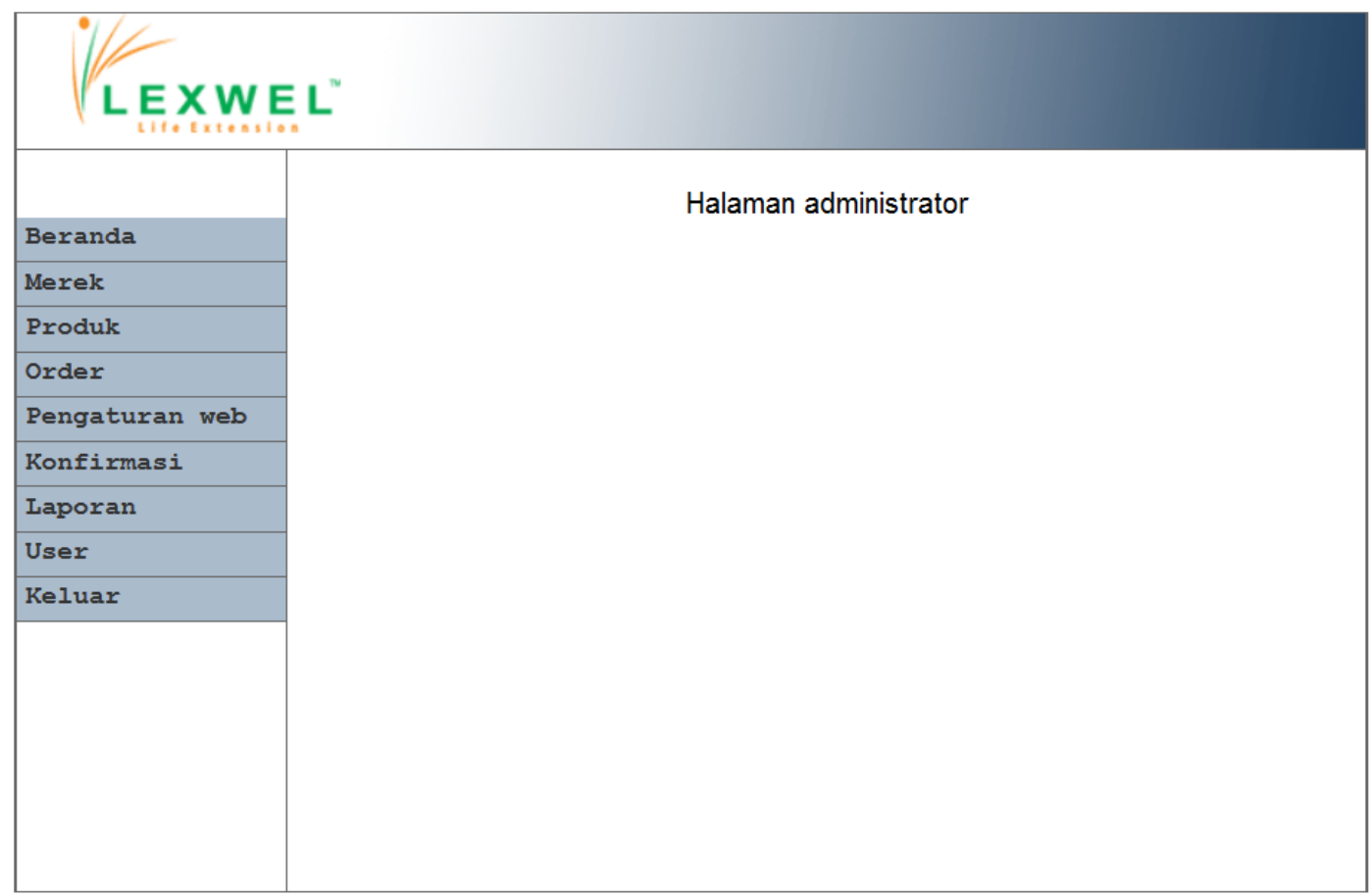

Gambar 6. Halaman sistem manajemen konten. 


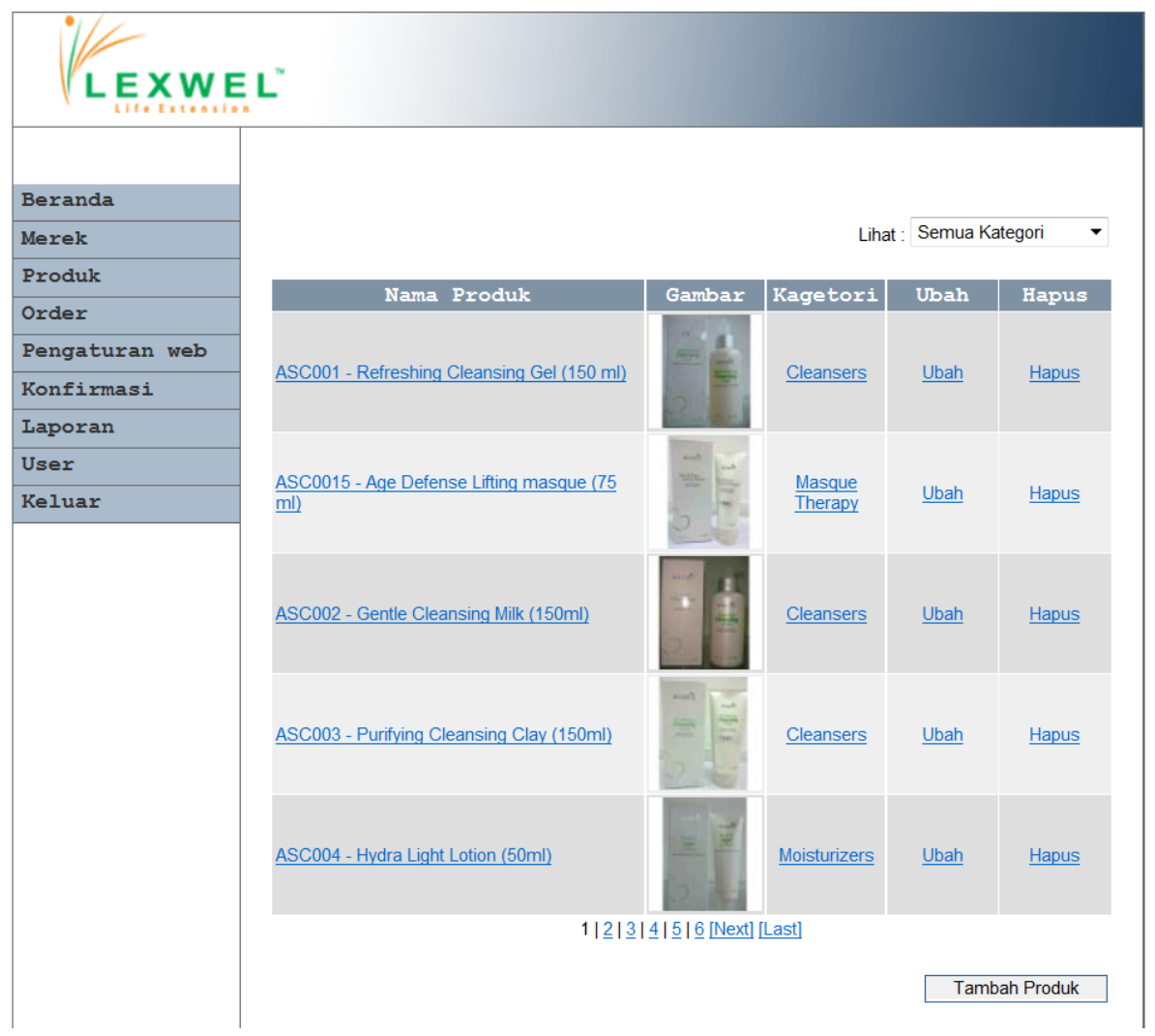

Gambar 7. Halaman tambah produk.

\section{PENUTUP}

Berdasarkan analisis yang telah lakukan, PT EIGL memiliki peluang untuk memanfaatkan $e$ commerce dan aplikasi $e$-commerce yang diusulkan dalam bentuk prototipe. Aplikasi ini memiliki fitur profile perusahaan, produk (penjelasan dan harga), cara pembayaran, user, pemesanan produk online, pengecekan status pemesanan, serta pembuatan laporan penjualan. Dengan memanfaatkan $e$ commerce, pelanggan dapat melakukan pemesanan produk melalui website yang telah dirancang. Selain itu, pelanggan juga dapat melihat status pemesanan melalui website sehingga pelanggan dapat mengetahui status pemesanan produknya.

\section{DAFTAR PUSTAKA}

Mathiassen, L., Madsen, A. M., Nielsen, P. A., and Stage, J. (2000). Object-Oriented Analysis and Design. Aalborg: Marko Publishing.

O'Brien, James A. (2005). Jakarta: Pengantar Sistem Informasi. Jakarta: Salemba Empat.

Rayport, J. F., Jaworski, B. J. (2003). Introduction to E-commerce, (2 ${ }^{\text {nd }}$ ed.). Singapore: McGraw-Hill.

Situs bataviase.co.id. (2010). Pertumbuhan Penjualan Kosmetik Lokal Macet. Diakses dari http://bataviase.co.id/node/354061. 